\title{
Anergic B Cells: Precarious On-Call Warriors at the Nexus of Autoimmunity and False-Flagged Pathogens
}

\author{
Allen J. Rosenspire ${ }^{1 *}$ and Kang Chen ${ }^{1,2,3,4,5,6}$ \\ ${ }^{1}$ Department of Immunology and Microbiology, Wayne State University, Detroit, MI, USA, ${ }^{2}$ Department of Obstetrics and \\ Gynecology, Wayne State University, Detroit, MI, USA, ${ }^{3}$ Department of Oncology, Wayne State University, Detroit, MI, USA, \\ ${ }^{4}$ Perinatology Research Branch, Eunice Kennedy Shriver National Institute of Child Health and Human Development, National \\ Institutes of Health, Detroit, MI, USA, ${ }^{5}$ Tumor Biology and Microenvironment Program, Barbara Ann Karmanos Cancer \\ Institute, Detroit, MI, USA, ${ }^{6}$ Mucosal Immunology Studies Team, National Institute of Allergy and Infectious Diseases, National \\ Institutes of Health, Bethesda, MD, USA
}

Keywords: B cell, anergy, autoimmunity, infection, vaccines, immunotherapy of cancer

\section{OPEN ACCESS}

Edited by:

Harry W. Schroeder, University of Alabama at Birmingham,

Reviewed by:

Subbarao Bondada

University of Kentucky, USA Laurence Morel,

University of Florida, USA

*Correspondence:

Allen J. Rosenspire arosenspire@wayne.edu

Specialty section: This article was submitted to $B$ Cell Biology, a section of the journal Frontiers in Immunology

Received: 27 July 2015 Accepted: 30 October 2015 Published: 26 November 2015

Citation:

Rosenspire AJ and Chen K (2015)

Anergic $B$ Cells: Precarious On-Call Warriors at the Nexus of Autoimmunity and False-Flagged Pathogens.

Front. Immunol. 6:580. doi: 10.3389/fimmu.2015.00580
A tenet of modern immunology is that the adaptive immune system has evolved so as to prevent, or at least diminish responses targeting self-antigens (1). Self-reactive B cells that arise due to incomplete negative selection in the bone marrow have been shown to be removed or inactivated in the periphery, with the most strongly self-reactive cells subject to clonal deletion. Less self-reactive cells either undergo receptor editing or are rendered anergic $(2,3)$. Receptor editing entails the reactivation of recombinase activating genes (RAGs) and enables immunoglobulin genes to be rearranged to create new antigen specificities. Anergy is a poorly understood state whereby cells retain the ability to bind to self-antigens but are otherwise rendered insensitive to antigenic stimulation (4). However, anergy is not a perfect solution to control self-reactivity. Many multifactorial autoimmune disorders involve the disruption of $B$ cell anergy as a potential mechanism (5). One of the best known examples is systemic lupus erythematosus (SLE), where the inappropriate activation of anergic B cells and their differentiation into plasma cells that secrete autoreactive antibodies are an important contributing pathogenic mechanism. In particular, a large number of the autoantibodies in SLE is of the 9G4 idiotype (6). It has been shown that 9G4 idiotypic B cells are present and anergic in normal individuals, but actively expand into the plasma and memory cell compartments in SLE patients (7).

Much effort has been devoted to delineating the molecular differences in the signaling pathways between anergic and normal $\mathrm{B}$ cells, in order to understand their difference in the ability to respond to antigenic stimulation. Multiple mechanisms are likely involved. For instance, anergic $B$ cells differ from normal B cells in the functioning of several signaling elements down-stream of the B cell receptor, such as the tyrosine kinase Lyn and the tyrosine phosphatase SHIP-1 (4). It has also been shown that a population of human peripheral blood naive B cells expressing autoreactive $\operatorname{IgD}$ receptor but no IgM receptor is anergic (8), and the responsiveness of B cells to low valence antigens was decreased by the flexible hinge region of $\operatorname{IgD}(9)$, suggesting that switching the $\mathrm{B}$ cell receptor usage from IgM to IgD resulting in higher IgD/IgM ratios may be a means to achieve anergy.

Related studies have focused on the mechanisms that permit anergic B cell activation in the context of autoimmune diseases (7). Lost in the mechanistic discussions, however, has been the question as to why anergic B cells exist in the first place. After all, these are dangerous cells, which could have been easily removed by clonal deletion early on during B cell development. Their persistence in the periphery implies to us that they must serve some immunological 


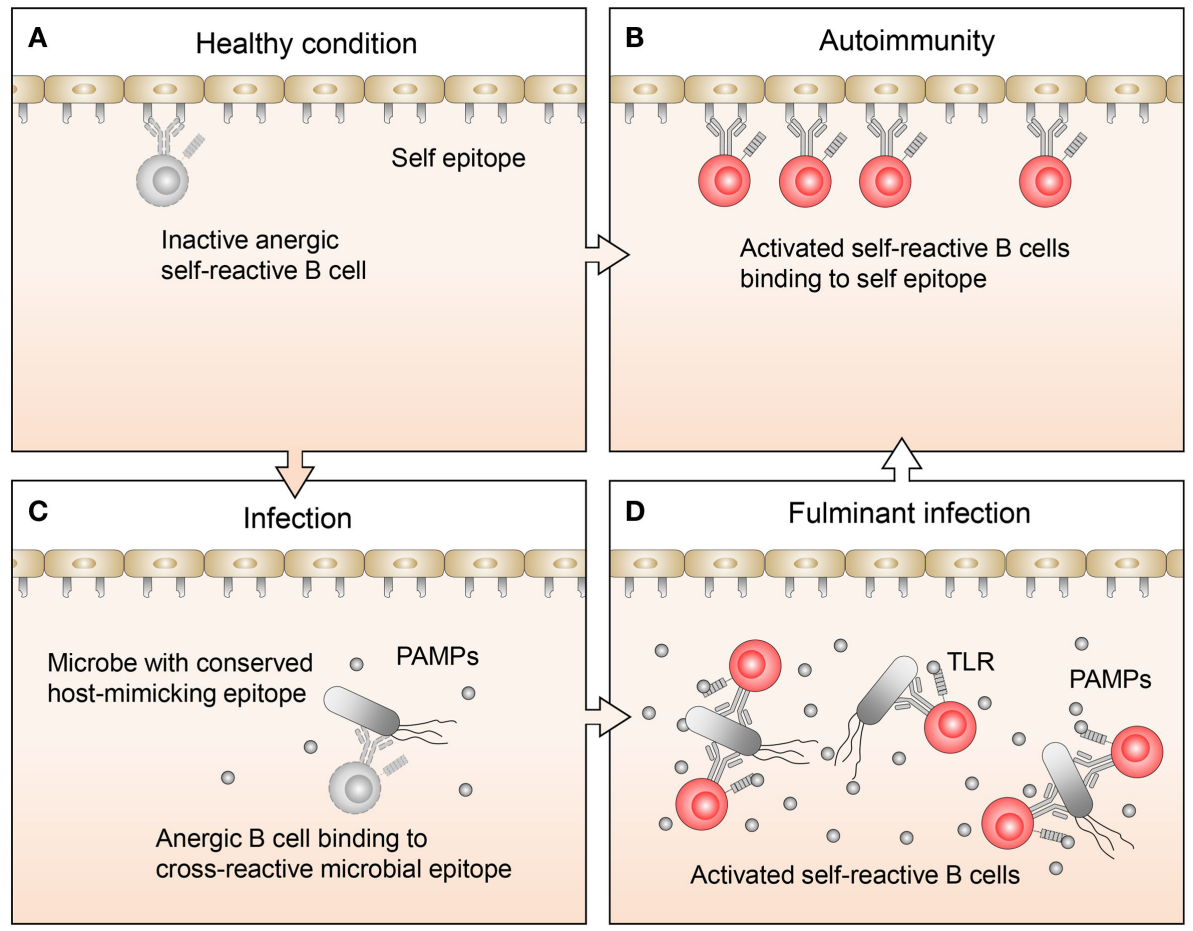

FIGURE 1 | Proposed regulation and function of anergic B cells. (A) Under healthy conditions, there are a limited number of self-reactive B cells. These cells are mostly restricted to the anergic B cell pool, so while they may bind self-antigens, they are not activated. (B) In autoimmune disease, anergic B cells often bind to self-antigen, become activated, and respond by transitioning out of the anergic B cell pool, leading to an expansion of self-reactive B cells. (C) Normally during infections, B cells, which recognize pathogen-specific antigens clonally expand. If the pathogen also expresses host-mimicking epitopes, anergic B cells which recognize these epitopes may bind but are not activated because the levels of pathogen-associated molecular pattern (PAMP) molecules are low. (D) Under conditions where an infection becomes fulminant and PAMP levels are elevated, TLR signaling may synergize with signals from the BCR on anergic B cells, allowing them to transition out of the anergic B cell pool. This will lead to an expansion of activated B cells, which recognize host-mimicking epitopes on the pathogen, as well as antigens on host tissues.

function. Recently, studies on B cell exhaustion associated with certain chronic infection $(10,11)$ suggest that rescue from anergy by proper stimuli may in some cases be a necessary measure to fight infections. We agree that rescue from anergy may in some instances be necessary to fight infection, and further contend that the molecular underpinning of this phenomenon may involve the cross-reactivity of the pathogens with the host (Figure 1).

Pathogens often have cross-reactive antigens with their host. It is for this reason that streptococci infections responsible for rheumatic fever can result in the production of autoantibodies targeting heart valves (12). Likewise, coxsackie virus infections can provoke the production of autoantibodies targeting the heart (13, 14). There are numerous other examples of the causal association between pathogen infection and autoantibody production. In fact, it is generally believed that viruses and bacteria are among the environmental triggers of autoimmune diseases (15). However, it has commonly been thought that when autoimmunity occurs as a result of infection, the appearance of cross-reactivity between pathogenic and self-antigens is serendipitous.

We propose that the appearance of antigenic mimicry between pathogens and their host is the result of an evolutionary adaptation, whereby pathogens protect themselves from the host's immune response by co-evolving with their host vital antigenic epitopes with immunological similarity to host antigens. In other words, these vital pathogen epitopes are protected because they would not trigger the host's immune system, as they appear to be self to the host. In a military analogy, they are wearing deceptive uniforms and are "false flagged." It is our view that anergy reflects a counter-balancing host adaption enabling adaptive immunity to deal with "falsely flagged" pathogens. We suggest that anergic B cells are held in abeyance until such time as when they are absolutely needed to neutralize an infection and the issue of autoimmunity has become of secondary importance. In this way, anergic B cells would serve as a cellular reservoir that can be deployed when needed to expand the immune repertoire to include antibodies targeting vital epitopes on pathogenic organisms which are normally hidden from immune surveillance by cloaking themselves via cross-reactivity with antigens of the host. This view is in accord with a previous suggestion that anergic B cells, aside as serving as a reservoir of cells responsible for autoantibodies that characterize rheumatic diseases, may also serve a useful function for protective immunity (16).

This circle of ideas is perhaps best supported by recent experience with human immunodeficiency virus (HIV) where a connection between the ability to generate broadly neutralizing antibodies (BNAs) to HIV and autoimmunity has been found $(17,18)$. Almost from the beginning of the HIV epidemic, it 
has been observed that the incidence of HIV in SLE is significantly lower than that in the general population as a whole (19). Recently, it has been shown that this epidemiological finding can likely be explained by the fact that SLE seems to be linked to the ability to make BNAs to HIV (20). Interestingly, 9G4 autoreactivity, the marker for SLE as discussed above, is increased in HIV-infected patients, and correlates with HIV BNA activity, suggesting that production of BNAs is connected to a loss of tolerance $(21,22)$. Furthermore, it has also been found that naturally arising BNAs, whether from SLE patients or not, almost invariably possess some level of autoreactivity $(23,24)$. In fact, a recent review surveying over 120 BNAs reported that all of them were associated with relaxation of host tolerance (23). In a related vein, it has been found that genetic variants associated with psoriasis are also protective against HIV-1 disease (25). Although in this case the presence of BNA was not investigated, again the implication is that not just SLE, but autoimmunity in general may be associated with the ability to produce BNAs to HIV.

Recent findings show that BNAs, when they are produced tend to bind to only a few select epitopes of the HIV trimer (26). In the context of the autoimmune phenomena discussed above, the conclusion that we draw is that those determinants on HIV to which BNA are reactive are strategically important for virus function. We suspect that in general they are difficult for the immune response to target, precisely because the virus has evolved in such a way as to protect them by making these determinants cross-reactive with a host antigen. The idea that a pathogen can escape immune detection by mimicking host epitopes has recently been suggested to apply to bacterial pathogens with respect to capsular polysaccharides which are structurally similar to host polysaccharides (27). Accordingly, a prerequisite for initiating an immune response targeting cross-reactive epitopes is that the immune repertoire first be expanded to insure such epitopes are able to appropriately interact with a receptive $B$ cell. We propose that the source of this expanded repertoire is the anergic $B$ cell pool.

Following this argument, one might ask, how can anergic cells be part of the normal adaptive immune response if they are ultimately responsible for autoimmunity? However, as we have pointed out above, exposure to pathogens often does give rise to autoimmunity and autoimmune diseases! A more relevant question might be, if anergic cells are part of the normal adaptive immune response, why do not we see more autoimmune diseases? The answer would appear to be that this is precisely why anergic cells are held under such tight control. We assume that they would be only called upon as a last resort of contingency, when other cellular components of the immune system have failed to control an infection. At this point, the immediate concern of the host would likely be control of acute infection, with potential chronic autoimmune considerations of secondary importance.

The question arises as to how the immune system might call these reserve anergic cells into action when the need arises. Although this is an open question, we suggest that toll-like receptors (TLRs) will turn out to be an important part of the answer. It is well known that TLRs provide complementary stimulatory signals to B cells upon binding pathogen-associated molecules such as CpG DNA and LPS (28). It has been shown by multiple investigators that anergic cells respond to TLR4 stimulation, as anergy can be partially broken in human and mouse anergic $\mathrm{B}$ cells by exposure to LPS, albeit at higher concentrations than those needed to activate non-anergic B cells (29-34). More recently, it has been shown that signaling through TLRs other than TLR4 likely can also break anergy, as detection of nucleic acids by TLRs is also linked to SLE (35).

In any event, it is not too hard to envisage that when normal immune mechanisms fail to resolve infections, such as in a fulminant infection, high levels of TLR agonists, pathogenassociated molecular pattern (PAMP) molecules will result. We expect that it is only under conditions of abnormally high levels of PAMPs that anergic cells respond to TLR signaling, potentially overcoming quiescence in antigen-stimulated anergic B cells. In this way, it may be molecularly and immunologically possible to release anergy in a controlled fashion, only when needed. However, if this is true, then it would also be predicted that TLR stimulation of anergic B cells would also be associated with autoimmunity. In support of this idea, we note that TLRs and the MyD88 signaling pathway have been shown to play an essential role in the generation of autoantibodies in mouse models of autoimmunity (36-40). It has, in fact, been previously suggested that bacteria-derived LPS could circumvent normal tolerogenic controls and thereby contribute to the generation of autoimmune disease (34).

The association of TLRs with models of autoimmunity may represent situations where TLRs have been coaxed to aberrantly activate anergic B cells. Generally, we would expect that the activation of anergic B cells would not always lead to excessive autoimmunity. Although pathogenic antigens might be crossreactive with host antigens, they would not be expected to be identical. In this case, affinity maturation in the germinal centers over time would be expected to drive the immune response to more closely target the pathogenic epitopes, rather than self. This idea is supported by findings that show that DNA sequences associated with BNA HIV antibodies are highly mutated from germ line sequences, as they are the products of multiple rounds of affinity maturation lasting of the order of perhaps 2 or more years (41-43).

Finally, experiments demonstrating association of TLRs with models of autoimmunity may provide insight into how we might activate anergic cells for useful therapeutic purposes. For instance, returning to the problem of developing an HIV vaccine, we might want to explore the use of targeting TLRs on anergic B cells as a way of expanding the immune repertoire prior to inoculations with HIV-specific antigens. Likewise in immunotherapy, tumorassociated antigens are in most instances not uniquely expressed on tumor cells, so that raising an immune response to a tumor is in many respects akin to raising an autoimmune response, although to a much more limited extent than is usually associated with autoimmunity. Nevertheless, if reactivity to tumorassociated antigens is represented in the immune repertoire of anergic cells, then activation of these cells through manipulation of TLRs prior to immunization with "tumor-specific" antigens might prove beneficial. 


\section{ACKNOWLEDGMENTS}

The authors would like to thank Dr. Kendall A. Smith for helpful discussions.

\section{FUNDING}

This work was supported by grants from the National Institute of Environmental Health Sciences R21 ES21285, R21 ES24476,

\section{REFERENCES}

1. Janeway CA, Travers P, Walport M, Shlomchik M. Chapter 1: Basic Concepts in Immunology, Immunobiology: The Immune System in Health and Disease. New York, NY: Garland Science (2006).

2. Janeway CA, Travers P, Walport M, Shlomchik M. Chapter 7: The Development and Survival of Lymphocytes, Immunobiology: The Immune System in Health and Disease. New York, NY: Garland Science (2006).

3. Wesemann DR, Portuguese AJ, Meyers RM, Gallagher MP, Cluff-Jones K, Magee JM, et al. Microbial colonization influences early B-lineage development in the gut lamina propria. Nature (2013) 501:112-5. doi:10.1038/nature12496

4. Yarkoni Y, Getahun A, Cambier JC. Molecular underpinning of B-cell anergy. Immunol Rev (2010) 237:249-63. doi:10.1111/j.1600-065X.2010.00936.x

5. Conrad FJ, Rice JS, Cambier JC. Multiple paths to loss of anergy and gain of autoimmunity. Autoimmunity (2007) 40:418-24. doi:10.1080/ 08916930701464723

6. Isenberg D, Spellerberg M, Williams W, Griffiths M, Stevenson F. Identification of the 9G4 idiotope in systemic lupus erythematosus. Br J Rheumatol (1993) 32:876-82. doi:10.1093/rheumatology/32.10.876

7. Cappione A III, Anolik JH, Pugh-Bernard A, Barnard J, Dutcher P, Silverman $\mathrm{G}$, et al. Germinal center exclusion of autoreactive B cells is defective in human systemic lupus erythematosus. J Clin Invest (2005) 115:3205-16. doi:10.1172/ JCI24179

8. Duty JA, Szodoray P, Zheng NY, Koelsch KA, Zhang Q, Swiatkowski M, et al. Functional anergy in a subpopulation of naive B cells from healthy humans that express autoreactive immunoglobulin receptors. J Exp Med (2009) 206:139-51. doi:10.1084/jem.20080611

9. Ubelhart R, Hug E, Bach MP, Wossning T, Duhren-von Minden M, Horn AH, et al. Responsiveness of B cells is regulated by the hinge region of $\operatorname{IgD}$. Nat Immunol (2015) 16:534-43. doi:10.1038/ni.3141

10. Moir S, Malaspina A, Ogwaro KM, Donoghue ET, Hallahan CW, Ehler LA, et al. HIV-1 induces phenotypic and functional perturbations of B cells in chronically infected individuals. Proc Natl Acad Sci U S A (2001) 98:10362-7. doi:10.1073/pnas.181347898

11. Moir S, Ho J, Malaspina A, Wang W, DiPoto AC, O'Shea MA, et al. Evidence for HIV-associated B cell exhaustion in a dysfunctional memory B cell compartment in HIV-infected viremic individuals. J Exp Med (2008) 205:1797-805. doi:10.1084/jem.20072683

12. Galvin JE, Hemric ME, Ward K, Cunningham MW. Cytotoxic mAb from rheumatic carditis recognizes heart valves and laminin. J Clin Invest (2000) 106:217-24. doi:10.1172/JCI7132

13. Maisch B, Bauer E, Cirsi M, Kochsiek K. Cytolytic cross-reactive antibodies directed against the cardiac membrane and viral proteins in coxsackievirus B3 and B4 myocarditis. Characterization and pathogenetic relevance. Circulation (1993) 87:IV49-65.

14. Latif N, Zhang H, Archard LC, Yacoub MH, Dunn MJ. Characterization of antiheart antibodies in mice after infection with coxsackie B3 virus. Clin Immunol (1999) 91:90-8. doi:10.1006/clim.1998.4679

15. Ercolini AM, Miller SD. The role of infections in autoimmune disease. Clin Exp Immunol (2009) 155:1-15. doi:10.1111/j.1365-2249.2008.03834.x

16. Zikherman J, Parameswaran R, Weiss A. Endogenous antigen tunes the responsiveness of naive B cells but not T cells. Nature (2012) 489:160-4. doi:10.1038/ nature 11311

17. Mascola JR, Haynes BF. HIV-1 neutralizing antibodies: understanding nature's pathways. Immunol Rev (2013) 254:225-44. doi:10.1111/imr.12075 and P30 ES20957 (AR); National Institute of Allergy and Infectious Diseases Mucosal Immunology Studies Team (MIST) U01 AI95776, Young Investigator Award, National Cancer Institute Cancer Center Support Grant P30 CA22453, Burroughs Wellcome Fund, American Congress of Obstetricians and Gynecologists, Wayne State University Maternal, Perinatal, and Child Health Initiative and Wayne State University Office of the vice President for Research (KC).

18. Bonsignori M. Will studies in individuals with systemic lupus erythematosus be the key to future HIV vaccine design? Expert Rev Vaccines (2014) 13:1271-3. doi:10.1586/14760584.2014.938056

19. Kudva YC, Peterson LS, Holley KE, Wright AJ, Hunder GG. SLE nephropathy in a patient with HIV infection: case report and review of the literature. $J$ Rheumatol (1996) 23:1811-5.

20. Bonsignori M, Wiehe K, Grimm SK, Lynch R, Yang G, Kozink DM, et al. An autoreactive antibody from an SLE/HIV-1 individual broadly neutralizes HIV-1. J Clin Invest (2014) 124:1835-43. doi:10.1172/JCI73441

21. Kobie JJ, Alcena DC, Zheng B, Bryk P, Mattiacio JL, Brewer M, et al. 9G4 autoreactivity is increased in HIV-infected patients and correlates with HIV broadly neutralizing serum activity. PLoS One (2012) 7:e35356. doi:10.1371/ journal.pone.0035356

22. Alcena DC, Kobie JJ, Kaminski DA, Rosenberg AF, Mattiacio JL, Brewer M, et al. 9G4+ antibodies isolated from HIV-infected patients neutralize HIV-1 and have distinct autoreactivity profiles. PLoS One (2013) 8:e85098. doi:10.1371/ journal.pone.0085098

23. Verkoczy L, Diaz M. Autoreactivity in HIV-1 broadly neutralizing antibodies: implications for their function and induction by vaccination. Curr Opin HIV AIDS (2014) 9:224-34. doi:10.1097/COH.0000000000000049

24. Kobie JJ, Zheng B, Piepenbrink MS, Hessell AJ, Haigwood NL, Keefer $\mathrm{MC}$, et al. Functional and molecular characteristics of novel and conserved cross-clade HIV envelope specific human monoclonal antibodies. Monoclon Antib Immunodiagn Immunother (2015) 34:65-72. doi:10.1089/mab. 2014.0064

25. Chen H, Hayashi G, Lai OY, Dilthey A, Kuebler PJ, Wong TV, et al. Psoriasis patients are enriched for genetic variants that protect against HIV-1 disease. PLoS Genet (2012) 8:e1002514. doi:10.1371/journal.pgen.1002514

26. Burton DR, Mascola JR. Antibody responses to envelope glycoproteins in HIV-1 infection. Nat Immunol (2015) 16:571-6. doi:10.1038/ni.3158

27. Cress BF, Englaender JA, He W, Kasper D, Linhardt RJ, Koffas MA. Masquerading microbial pathogens: capsular polysaccharides mimic host-tissue molecules. FEMS Microbiol Rev (2014) 38:660-97. doi:10.1111/1574-6976.12056

28. Pasare C, Medzhitov R. Control of B-cell responses by toll-like receptors. Nature (2005) 438:364-8. doi:10.1038/nature04267

29. Pike BL, Abrams J, Nossal GJ. Clonal anergy: inhibition of antigen-driven proliferation among single B lymphocytes from tolerant animals, and partial breakage of anergy by mitogens. Eur J Immunol (1983) 13:214-20. doi:10.1002/ eji. 1830130307

30. Tsao BP, Chow A, Cheroutre H, Song YW, McGrath ME, Kronenberg M. B cells are anergic in transgenic mice that express IgM anti-DNA antibodies. Eur J Immunol (1993) 23:2332-9. doi:10.1002/eji.1830230942

31. Noorchashm H, Bui A, Li HL, Eaton A, Mandik-Nayak L, Sokol C, et al. Characterization of anergic anti-DNA B cells: B cell anergy is a T cell-independent and potentially reversible process. Int Immunol (1999) 11:765-76. doi:10.1093/ intimm/11.5.765

32. Adams E, Basten A, Goodnow CC. Intrinsic B-cell hyporesponsiveness accounts for self-tolerance in lysozyme/anti-lysozyme double-transgenic mice. Proc Natl Acad Sci U S A (1990) 87:5687-91. doi:10.1073/pnas.87.15.5687

33. Chu YP, Taylor D, Yan HG, Diamond B, Spatz L. Persistence of partially functional double-stranded (ds) DNA binding B cells in mice transgenic for the IgM heavy chain of an anti-dsDNA antibody. Int Immunol (2002) 14:45-54. doi:10.1093/intimm/14.1.45

34. Phan TG, Amesbury M, Gardam S, Crosbie J, Hasbold J, Hodgkin PD, et al. $\mathrm{B}$ cell receptor-independent stimuli trigger immunoglobulin (Ig) class switch 
recombination and production of IgG autoantibodies by anergic self-reactive B cells. J Exp Med (2003) 197:845-60. doi:10.1084/jem.20022144

35. Teichmann LL, Schenten D, Medzhitov R, Kashgarian M, Shlomchik MJ. Signals via the adaptor MyD88 in B cells and DCs make distinct and synergistic contributions to immune activation and tissue damage in lupus. Immunity (2013) 38:528-40. doi:10.1016/j.immuni.2012.11.017

36. Leadbetter EA, Rifkin IR, Hohlbaum AM, Beaudette BC, Shlomchik MJ, Marshak-Rothstein A. Chromatin-IgG complexes activate B cells by dual engagement of IgM and toll-like receptors. Nature (2002) 416:603-7. doi:10. $1038 / 416603 a$

37. Herlands RA, Christensen SR, Sweet RA, Hershberg U, Shlomchik MJ. T cell-independent and toll-like receptor-dependent antigen-driven activation of autoreactive B cells. Immunity (2008) 29:249-60. doi:10.1016/j.immuni.2008. 06.009

38. Groom JR, Fletcher CA, Walters SN, Grey ST, Watt SV, Sweet MJ, et al. BAFF and MyD88 signals promote a lupuslike disease independent of T cells. J Exp Med (2007) 204:1959-71. doi:10.1084/jem.20062567

39. Ehlers M, Fukuyama H, McGaha TL, Aderem A, Ravetch JV. TLR9/MyD88 signaling is required for class switching to pathogenic IgG2a and $2 \mathrm{~b}$ autoantibodies in SLE. J Exp Med (2006) 203:553-61. doi:10.1084/jem.20052438

40. Becker-Herman S, Meyer-Bahlburg A, Schwartz MA, Jackson SW, Hudkins KL, Liu C, et al. WASp-deficient B cells play a critical, cell-intrinsic role in triggering autoimmunity. J Exp Med (2011) 208:2033-42. doi:10.1084/jem.20110200
41. Gray ES, Madiga MC, Hermanus T, Moore PL, Wibmer CK, Tumba NL, et al. The neutralization breadth of HIV-1 develops incrementally over four years and is associated with $\mathrm{CD} 4+\mathrm{T}$ cell decline and high viral load during acute infection. J Virol (2011) 85:4828-40. doi:10.1128/JVI.00198-11

42. Simek MD, Rida W, Priddy FH, Pung P, Carrow E, Laufer DS, et al. Human immunodeficiency virus type 1 elite neutralizers: individuals with broad and potent neutralizing activity identified by using a high-throughput neutralization assay together with an analytical selection algorithm. $J$ Virol (2009) 83:7337-48. doi:10.1128/JVI.00110-09

43. Shen X, Parks RJ, Montefiori DC, Kirchherr JL, Keele BF, Decker JM, et al. In vivo gp 41 antibodies targeting the $2 \mathrm{~F} 5$ monoclonal antibody epitope mediate human immunodeficiency virus type 1 neutralization breadth. J Virol (2009) 83:3617-25. doi:10.1128/JVI.02631-08

Conflict of Interest Statement: The authors declare that the research was conducted in the absence of any commercial or financial relationships that could be construed as a potential conflict of interest.

Copyright $(\odot 2015$ Rosenspire and Chen. This is an open-access article distributed under the terms of the Creative Commons Attribution License (CC BY). The use, distribution or reproduction in other forums is permitted, provided the original author(s) or licensor are credited and that the original publication in this journal is cited, in accordance with accepted academic practice. No use, distribution or reproduction is permitted which does not comply with these terms. 